\title{
Antecedent events in motor neuron disease
}

\author{
M GAWEL, ${ }^{*}$ Z ZAIWALLA, F CLIFFORD ROSE \\ From the Department of Neurology, Charing Cross Hospital, London, UK
}

SUMMARY Sixty-three patients with motor neuron disease and sixty-one controls matched for age and sex were interviewed concerning life events. An antecedent history of back injuries was found more often and there was an increased incidence of prior electric shock amongst the patients. No increase of head injuries, fractures, malignancy or previous poliomyelites was detected.

Motor neuron disease is a disorder of unknown aetiology. There have been many theories concerning its pathogenesis ranging from toxic factors to immunological disturbances. It is appropriate that a study be made of antecedent events in order to seek any possible causative factor among individuals who developed the disease subsequently. In previous studies many risk factors for the development of motor neuron disease have been suggested. Mulder ${ }^{1}$ suggested that there was an over representation of previous poliomyelitis infection among sufferers. Haynal $^{2}$ felt that electric shock predisposed to development of the disorder. Ask Upmark ${ }^{3}$ described five cases following subtotal gastrectomy. Kondo $^{4}$ reinvestigated the evidence for this being a relevant factor and concluded that it was not. Kahle ${ }^{5}$ suggested that tonsillectomy may predispose to motor neuron disease especially the bulbar variety. Felmus et $a l^{6}$ performed a case control study with 25 consecutive cases of motor neuron disease admitted to hospital. They compared the responses to a questionnaire with sex and age matched patients from the neurology service. In this series $24 \%$ of the motor neuron disease group gave a history of heavy exposure to lead compared to $8 \%$ of the disease controls the difference being statistically significant. They found that the patients with motor neuron disease had an increased chance of having had an

*Dr MJ Gawel, Department of Neurological Sciences, Sunnybrook Medical Centre, 2075 Bayview Avenue, Toronto, Ontario, Canada M4N 3M5.

Address for reprint requests: Dr F Clifford Rose. Department of Neurology. Charing Cross Hospital, London U6 8RF.

Received 6 February 1983 and in revised form 14 May 1983 Accepted 2 June 1983 exposure to other heavy metals. The patients with motor neuron disease had more history of athletic participation compared to the disease controls and also compared to the healthy controls. Milk drinking was also over-represented in the motor neuron disease groups as were fractures. The history of major and minor operations suggest "healthy" as compared to "non-disease" were equivalent in all the groups. Hanisch et al ${ }^{7}$ using the registry in the Los Angeles area examined 116 cases of motor neuron disease with nearest neighbour controls. The only positive finding was that there was an increased history of exposure to animal carcasses and hides, there was also an increased incidence of patients with family members with motor neuron disease. Hawkes and $\mathrm{Fox}^{8}$ found an increased incidence of motor neuron disease in leather workers. Campbell et al ${ }^{9}$ examined the exposure to lead in 74 cases of motor neuron disease. Fifteen per cent gave a history of extensive exposure to lead compared with $5.4 \%$ of a control group. Twenty-five per cent of the patients compared to $9.4 \%$ of the controls had skeletal disease or skeletal fractures in the past. Beebe and Kurtzke ${ }^{10}$ performed a case control study based on Veterans records. They found a statistically significant excess of operations and injuries in the motor neuron disease group. Matched pair analysis gave essentially the same results. About a half of the operations were tonsillectomies or appendectomies. Injuries were more common in the motor neuron disease cases. Limb injuries were responsible for the difference between the groups. Operations were performed on $5.8 \%$ of patients compared with $2.8 \%$ of controls, and $7.5 \%$ of patients had injuries compared with $3.2 \%$ of controls. In this study athletic activity was not related to injury. The authors felt 
that possibly the information concerning pre-service athletic activities was incomplete. Kondo and Tsubaki" ${ }^{1}$ performed two case control studies, one of which was retrospective involving 712 cases, and the other involved 158 patients. These consisted of surviving hospital patients with motor neuron disease in various arbitrary areas of Japan. Half of the control individuals were normal while the others were patients treated in the same hospital for various mild non-neurological diseases. The studies suggested that mechanical injuries were more frequently found in the patients, the figures being $34.7 \%$ compared with $21.6 \%$. There was however totally random distribution of the onset of motor neuron disease in relation to the area of the body previously injured. There was no relationship of occupation to the development of motor neuron disease. A previous history of poliomyelitis did not appear to be significant.

We therefore felt it appropriate to continue this line of inquiry and perform a case control study of antecedent and risk factors in motor neuron disease.

\section{Material and methods}

Patients were seen at Charing Cross Hospital, Department of Neurology and had been diagnosed as motor neuron disease by one of the study neurologists. A questionnaire which had been previously prepared based on a variety of demographic factors, clinical information, and possible risk factors was given to 63 patients and 61 controls matched as nearly as possible for age and sex.

\section{Results}

(1) AGE AND SEX

The mean age of the patients was 52.1 years $(M$ $47 \cdot 5, \mathrm{~F} \mathrm{56.7)}$ ) that of the controls $53 \cdot 5$ years (M 50.4, F 57.1). The age and sex distribution between patients and controls was not statistically significantly different. The occupation of the patients classified into manual, clerical, active and professional is given in table 1 . There were no differences between patients and controls in the history of athletic activity.

\section{(2) CLINICAL PRESENTATIONS}

(a) Site affected. Five males and 11 females presented with bulbar palsy, seven males and one female with progressive muscular atrophy, and 20 males and 19 females with predominantly spinal cord symptoms of the upper motor neuron type.

(b) Handedness verses side of first symptoms. This question related to patients who presented with clear but unilateral symptoms either in the hand or the leg. There was a distinct trend for patients who
Table 1

\begin{tabular}{llclll}
\hline Occupation & \multicolumn{2}{l}{ Patients } & & & \multicolumn{2}{l}{ Controls } \\
\cline { 2 - 3 } \cline { 5 - 6 } \cline { 5 - 6 } & Male & Female & & Male & Female \\
\hline Manual & 14 & 3 & & 12 & 2 \\
Clerical sedentary & 8 & 23 & & 7 & 19 \\
Active & 4 & 4 & & 5 & 4 \\
Professional & 5 & 2 & & 9 & 3 \\
\hline
\end{tabular}

were right handed to present with signs or symptoms on the left side of the body $(0 \cdot 10>p>0.05)$. Twenty-three out of 33 right-handed presented with left sided signs.

(3) ANTECEDENT EVENTS

(a) Injuries (table 2) Injuries to the back were found more frequently in patients as compared to the controls. On the other hand, fractures and head injuries were found less frequently in the patients than in the controls. Forty-two controls had a history of fractures or head injuries in the previous 5 years as opposed to 32 patients.

(4) ELECTRIC SHOCK

(table 2) Electric shock and being struck by lightning was more frequent in the patients that in controls. However the numbers struck by lightning or who had electric shocks was small in both groups.

\section{(5) OTHER CHRONIC DISEASES}

There was no evidence that any other disorders were associated with motor neuron disease in our sample. There were no cases of previous poliomyelitis patients, although one patient had a sister affected by poliomyelitis. One patient had also had pernicious anaemia, one had pemphigus, two patients had malignancy (one carcinoma of the prostate, and one skin carcinoma). One patient had a mixed tumour of the parotids. The mothers of 10 patients had had cancer while the mothers of five controls had had

Table 2 Prior back injury or electric shock in patients with motor neuron disease

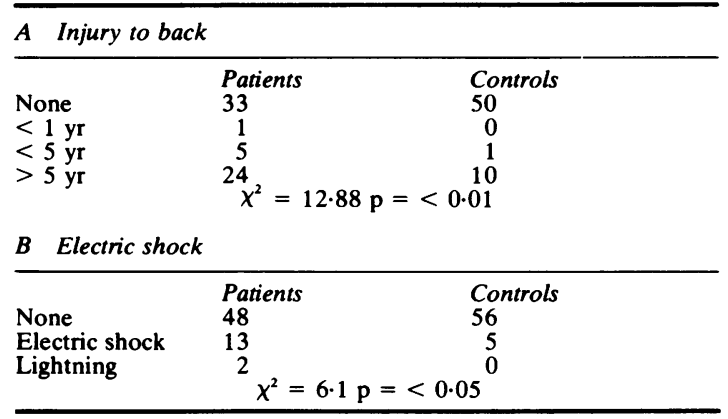


cancer. The fathers of five patients had had cancer while the fathers of eight controls had had cancer. Taking the questioning to second degree relatives, 43 patients relatives had malignancy, whereas 39 of the controls relatives had had malignancy.

\section{Discussion}

Our findings are compatible with the findings of Beebe and Kurtzke ${ }^{10}$ who found an increased incidence of spinal injuries when compared to controls. We did not find the excess of head injuries or fractures of the extremity found by these and other workers. The paper of Campbell et $a^{9}$ suggested that the skeletal fractures may be partly due to decalcification; although this is a possibility in patients with existing motor neuron disease, it is unlikely to be the case in patients in whom the fractures occurred 5 or so years prior to the onset of motor neuron disease. The negative association between fractures and head injuries and motor neuron disease suggest, at least, that these patients are not more likely to have falls, as was suggested by Kondo and Tsubaki. ${ }^{11}$ Any attempt to explain these findings on a pathophysiological basis can only be highly speculative, as these authors pointed out. There is no case with traumatic lesions co-existing with the changes of motor neuron disease suggesting a causal relationship.

The relationship of electrical injury to motor neuron disease is also interesting. One of the patients struck by lightning was a 28 -year-old stockbroker who was golfing when his umbrella was hit by a bolt of lightning and he was flung to the ground. Six months later the hand with which he had held the umbrella began to waste and following this came the changes of classical motor neuron disease with bulbar palsy. The case appears to suggest a more definite causal relationship and certainly electrical shock can cause marked damage to the nervous system although not usually producing classical motor neuron disease. A failure to find a history of past poliomyelitis or other chronic disorder is also interesting for it does not correspond to previous studies.

It would be necessary to examine a much larger population in order to make any definite statement concerning the role and relationship of injury in the development of motor neuron disease. This finding in a number of series is intriguing and probably warrants further study.

$\mathrm{ZZ}$ was supported by the MND Association of Great Britain.

\section{References}

' Mulder DW, Rosenbaum RA, Layton PD. Late progression of poliomyelitis or forme fruste amyotrophic lateral sclerosis. Mayo Clin Proc 1972;47:756.

${ }^{2}$ Haynal A, Regh F. Zusammenhang der Amyotrophischen Latersklerose mit gehauften Elektrotraumata, Conf Neurol 1964;24:189-98.

${ }^{3}$ Ask Upmark E. Amyotrophic lateral sclerosis observed in five patients after gastric resection. Gastroenterology (Baltimore) 1950;15:257-9.

${ }^{4}$ Kondo K. Does gastrectomy predispose to amyotrophic lateral sclerosis? Arch Neurol 1979;36:586-7.

${ }^{5}$ Kahle KW. Bulbarparalytische Verlaufsform der amyotrophischen Lateralsklerose nach Tonsillektomie und Tonsillitis. Dtsch Z Nervenheilkd 1956;174:573-82.

${ }^{6}$ Felmus MT, Pattern BM, Swanke L. Antecedent events in amyotrophic lateral sclerosis. Neurology (Minneap) 1976;26:167-72.

${ }^{7}$ Hanisch R, Dworsky RL, Henderson BE. A search for clues to the cause of amyotrophic lateral sclerosis. Arch Neurol 1976;33:456.

${ }^{8}$ Hawkes CG, Fox AJ. Motor neurone disease in leather workers. Lancet 1981;1:507.

9 Campbell AMG, Williams ER, Barltrop D. Motor neurone disease and exposure to lead. J Neurol Neurosurg Psychiatry 1970;33:877-85.

${ }^{10}$ Beebe GW, Kurtzke JF. Epidemiologic studies of amyotrophic lateral sclerosis. 1. A case control comparison based on ALS deaths. Am J Epidemiol 1977;106:245.

"Kondo K, Tsubaki T. Case control studies of motor neurone disease. Arch Neurol 1981;38:220-6. 